\title{
AVALIAÇÃO DA CONCENTRAÇÃO DE FERRO ORGÂNICO EM UMA POPULAÇÃO DE GRÁVIDAS *
}

\author{
Sophia Cornbluth Szarfarc** \\ Arnaldo Augusto F. de Siqueira*** \\ Ignez Salas Martins **
}

\begin{abstract}
SZARFARC, S. C. et al. Avaliação da concentração de ferro orgânico em uma população de grâvidas, Rev. Saúde públ., S. Paulo, 17:200-7, 1983.

RESUMO: Objetivou-se conhecer as alterações da concentração de hemoglobina $(\mathrm{Hb})$, hematócrito $(\mathrm{Ht})$, ferro sérico (FS), capacidade total de ligação de ferro (CTLF) e saturação de transferrina (ST) durante a gestação normal em mulheres não anêmicas ( $\mathrm{Hb} \geqslant 11,0 \mathrm{~g} / \mathrm{dl}$ ). Verificou-se, entre as 250 mulheres selecionadas, diminuição dos valores de $\mathrm{Hb}$ e $\mathrm{Ht}$ até $07^{\circ}$ mês de gravidez quando houve aumento nesses valores até o final do processo gravidico; o mesmo foi observado com relação aos valores do FS. A CTLF apresentou um aumento durante todo o periodo considerado enquanto a ST diminuiu. Os resultados observados justificam o uso de suplementação de ferro como uma estratégia de saúde pública a ser utilizada no controle da deficiência de ferro, mesmo entre mulheres não anêmicas.
\end{abstract}

UNITERMOS: Gestantes, estado nutricional. Anemia ferropriva.

\section{INTRODUÇÃO}

A anemia ferropriva é largamente prevalente em todas as partes do mundo. Ela é definida como a condição que resulta da inabilidade do tecido eritropoiético de manter uma concentração normal de hemoglobina devido a um inadequado suprimento de ferro. A concentração de hemoglobina, portanto, acusa a presença de anemia que, no entanto, é resultado final de uma deficiência severa anterior que possivelmente exauriu os estoques marciais.

A mulher é mais do que o homem, sensivel a essa carência. A necessidade adicional de ferro durante a vida reprodutiva feminina, imposta pela menstruação, condi- ciona a redução dos estoques de ferro. $\mathrm{Na}$ gravidez, os dois processos substancialmente depletivos de ferro que ocorrem, crescimento feto-placentário e expansão de volume sangüineo, levam a gestante a se constituir no grupo populacional mais exposto ao risco de se tornar ferro deficiente.

Os efeitos deletérios da anemia, menor capacidade de trabaho $2.5,1 \%, 31$, maior susceptibilidade a infecçōes ${ }^{18 . * 3}$, são acrescidos nesse grupo. Vários autores consideram a anemia fator de tal importância que, mesmo isoladamente, aumenta significativamente $o$ risco gravidico 1,9,26. A gestante anêmica sofre uma sobrecarga no parto, transfor-

* Trabalho desenvolvido com auxílio financeiro da FAPESP (Processo ne 12 Med/761411).

* Do Departamento de Nutrição da Faculdade de Saúde Pública da USP - Av. Dr. Arnaldo 715 - 01255 - São Pauló, SP - Brasil.

** Do Departamento de Saúde Materno-Infantil da Faculdade de Saúde Pública da USP - Ar. Dr. Arnaldo 715 - 01255 - São Paulo. SP - Brasil. 
mando a perda fisiológica da dequitação em processo espoliativo.

Devi 10 observa que 20 a $40 \%$ das mortes maternas ocorridas em hospitais são causadas, direta ou indiretamente, por complicações decorrentes da anemia. Quando a gestante apresenta uma concentração baixa de hemoglobina, o recém-nascido tem maiores probabilidades de também apresentar baixa concentração ${ }^{30}$. Frequientemente é encontrada a relação da anemia com maior incidência de toxemia, com maiores coeficientes de natimortalidade e com aumento do número de abortos 11.112,14,15,22. A Organização Mundial da Saúde ${ }^{34}$ verificou, em diferentes partes do mundo, que 21 a $80 \%$ das gestantes são anêmicas e que 40 a $99 \%$ delas tem deficiência de ferro. Essa Organização refere-se à anemia severa como fator que afeta $\bigcirc$ desenrolar da gravidez, 0 desenvolvimento do feto e o seu peso ao nascer.

$O$ ferro tem sua absorção condicionada à qualidade da dieta; a presença de fitatos, fosfatos e outros quelantes inibem seu aproveitamento, enquanto que aminoácidos sulfurados, carnes em geral e ácido ascórbico, melhoram sua absorção 20,27.

De acordo com as recomendações do National Research Council ${ }^{25}$, durante a gestação são necessários aumentos de $11 \%$ de energia na dieta, quando comparada à da mulher não grávida, e um adicional diário de $30-60 \mathrm{mg}$ de ferro através de suplementação. Dado o estado fisiológico especial da mulher, a tentativa de obter o ferro por meio de aumento na ingestão de alimentos redundaria em acréscimo tão elevado no consumo energético que, concomitantemente, haveria maior risco gravídico por um ganho de peso excessivo. Assim, considerada a dificuldade de conseguir ingestão adequada de ferro através da dieta alimentar habitual, a suplementação vem sendo reco- mendada para a população de grávidas mesmo em áreas de baixa prevalência de anemia 17,29 .

Qualquer programa de intervenção, no entanto, somente pode ser escolhido após estimadas a extensão e a severidade da deficiência ${ }^{8}$. Especificamente no caso de gestantes, as alterações fisiológicas que ocorrem e modificam a concentração dos componentes sangüíneos tem que ser consideradas.

Este trabalho foi feito com o objetivo de conhecer as tendências de indicadores bioquimicos referentes a ferro entre gestantes sadias, não-anêmicas.

\section{METODOLOGIA}

A população amostrada foi constituída por 250 gestantes normais (que não apresentaram patologia própria ou associada à gravidez) e não anêmicas (concentração de hemoglobina igual ou superior a $11,0 \mathrm{~g} / \mathrm{d} 1$ ). Cada uma delas recebeu, no mínimo, 4 consultas de pré-natal tendo, pelo menos a primeira delas, ocorrido no primeiro trimestre de gestação. Na maioria das vezes, em cada consulta era colhida uma amostra de sangue. Não houve prescrição de medicamentos contendo ferro às mulheres selecionadas. O acompanhamento de pré-natal foi feito em Centro de Saúde-Escola, cuja qualidade é satisfatória ${ }^{6.7}$.

Foram determinados no sangue, hemoglobina $(\mathrm{Hb})^{32}$, hematócrito $(\mathrm{Ht})^{*}$, ferro sérico $(\mathrm{FS})^{3}$, capacidade total da ligação de ferro (CTLF) ${ }^{28}$ e saturação da transferrina (ST) ${ }^{* *}$. A distribuição dos resultados obtidos foi feita por idade gestacional, em semanas, bem como em meses.

Dos indicadores acima citados foram calculadas as médias e os desvioss-padrão.

\footnotetext{
* Centrifugação do sangue total em micro tubo heparinizado.

$* \mathrm{ST}=\frac{F \mathrm{~S}}{\mathrm{CTLF}} \times 100$
} 
SZARFARC, S.C. et al. Avaliação da concentração de farro orgân co em uma população de grávidas. Rev. Saúde públ., S. Paulo, 17:200-7, 1983

\section{RESULTADOS E COMENTARIOS}

A hemoglobina tem sido o indicador mals utilizado para caracterizar a carência orgânica de ferro. Os válores médios encontrados, distribuídos por semana de gestação (Tabela-Figura 1), apresentam uma diminuição seguida, no final da gravidez, de aumento. $\mathrm{O}$ maior valor médio de $\mathrm{Hb}$ foi observado no início da gestação $13,4 \mathrm{~g} / \mathrm{d} 1$, e o mínimo foi atingido no $7^{\circ}$ mês, aumentando no final do processo gravídico. A Figura 1 mostra o modelo de distribuição da hemoglobina, com as médias e desvios-padrão, mês a mês, da gravidez. Essa curva é superponível à obtida, enı 1945, pelo Medical Research Council, descrita por Hytten e Leitch ${ }^{16}$, que fazem uma revisão dos principais trabalhos relativos à variação da concentração de $\mathrm{Hb}$ durante a gravidez.

Com relação ao $\mathrm{Ht}$ (Tabela - Figura 2) o mesmo modelo de variação foi observado. $\mathrm{O}$ valor mínimo de $\mathrm{Ht}$ foi encontrado no $7^{\circ}$ mês de gestação, sendo que no final da gravidez encontramos valores semelhantes aos do início.

As Figuras 1 e 2 sugerem que, no inicio da gravidez, o feto atua prioritariamente na obtenção do ferro. Até atingir um equilíbrio com outras vias, ele será o sistema privilegiado na captação do mineral. Com isso, a medula óssea, até então a maior consumidora de ferro, passa a receber menor proporção deste. Possivelmente ocorrem juntos o equilibrio do sistema fetal com os outros mecanismos bioquímicos e o final do aumento da volemia ${ }^{16}$, ambos ao redor do $7^{\circ}$ mês da gravidez. A partir de então, a medula óssea consegue substrato em maior quantidade para formação de $\mathrm{Hb}$, aumentando sua concentração no sangue da gestante.

O mesmo tipo de tendência encontrada para $\mathrm{Hb}$ e $\mathrm{Ht}$ também foi observado para a concentração de ferro sérico no decorrer da gestação (Tabela - Figura 3).
A sugestão de interpretação das Figuras 1 e 2 , no entanto, não contradiz a idéia de que as necessidades de ferro da mulher aumentam durante toda a gravidez. A distribuição dos valores da concentração de FS (Tabela - Figura 3), retrato do potencial férrico advindo da alimentação e dos estoques marciais, colabora para essa sugestão. A medida em que a gravidez evolui, o valor de FS diminui, atingindo o minimo ao redor da $28^{a}$ semana, a partir de quando há um aumento pouco acentuado.

O FS é transportado no sangue ligado à transferrina. A concentração desta (Tabela - Figura 4) mostra aumento durante todo o desenvolvimento da gravidez. Ela varia de $320 \mu \mathrm{g} / \mathrm{d} 1$ no início do processo para $360 \mu \mathrm{g} / \mathrm{d} 1$ no final. Sendo a transferrina a proteina que regula os diversos sistemas captadores de ferro, aumentando sempre que uma situação assim o exija, um aumento constante sugere que a necessidade de ferro é aumentada durante todo o período gravídico, ainda que as exigências do feto e as determinadas pelo aumento da volemia tenham atingido um equilibrio metabólico.

A relação entre FS e CTLF, saturação de transferrina (ST), diminui de valor durante todo o processo gestacional (Tabela - Figura 5) passando de $33 \%$ no início a 19\% no final da gestação.

Assim, durante a gestação, aumenta a disponibilidade da proteina transportadora do ferro, há aumento da absorção do ferro alimentar (fato que ocorre em qualquer situação em que a demanda é aumentada ${ }^{24}$ ), porém a captação do ferro pelas vias metabólicas requisitadoras do mineral processase em velocidade maior, não permitindo manutenção dos valores iniciais da saturação de transferrina.

Uma vez que a ST mantém forte correlação com a concentração de ferro da medula óssea $4,19,21,24$, a relação FS/CTLF é um excelente indicador preditivo do risco de ocorrência de anemia ferropriva. 


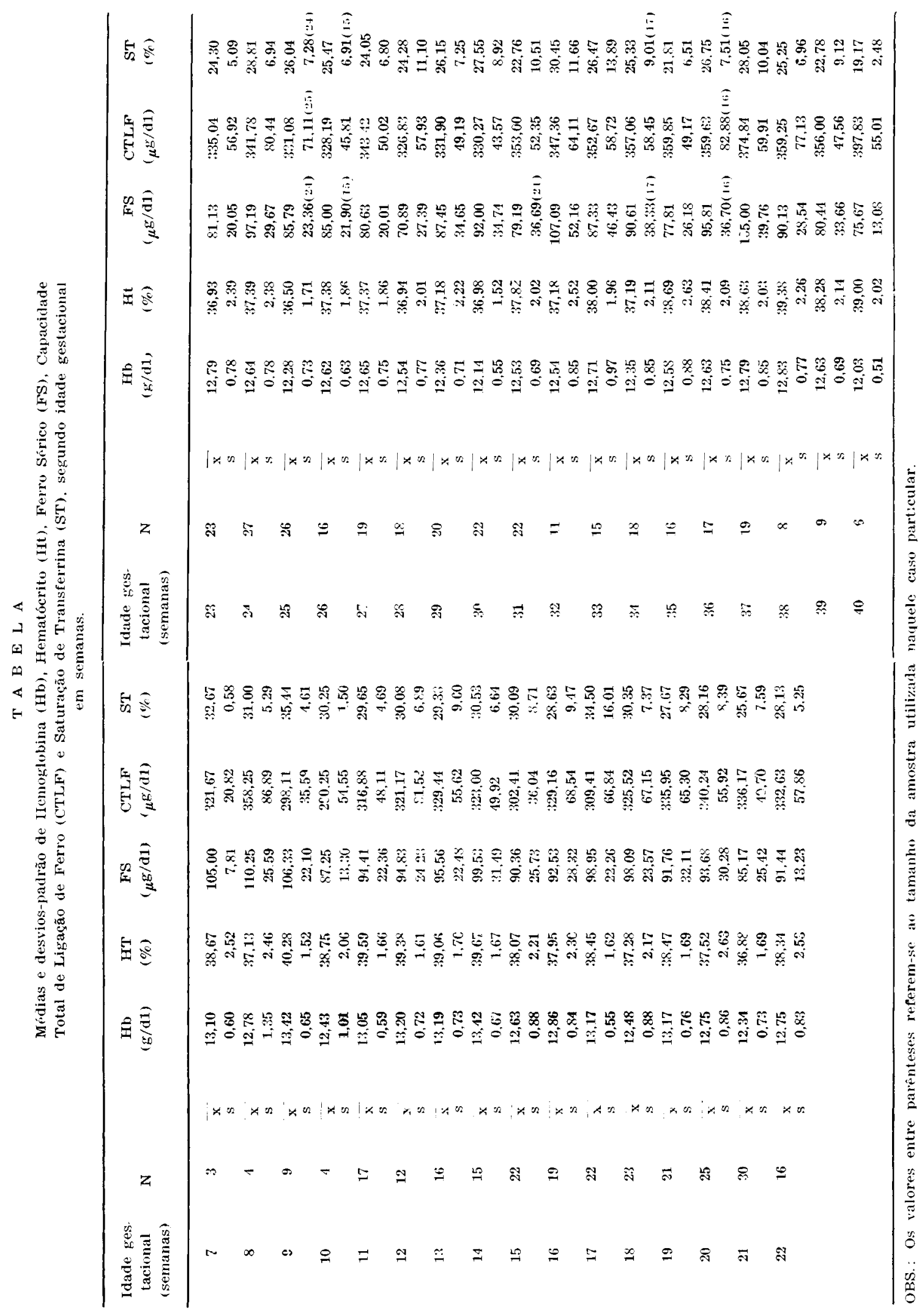




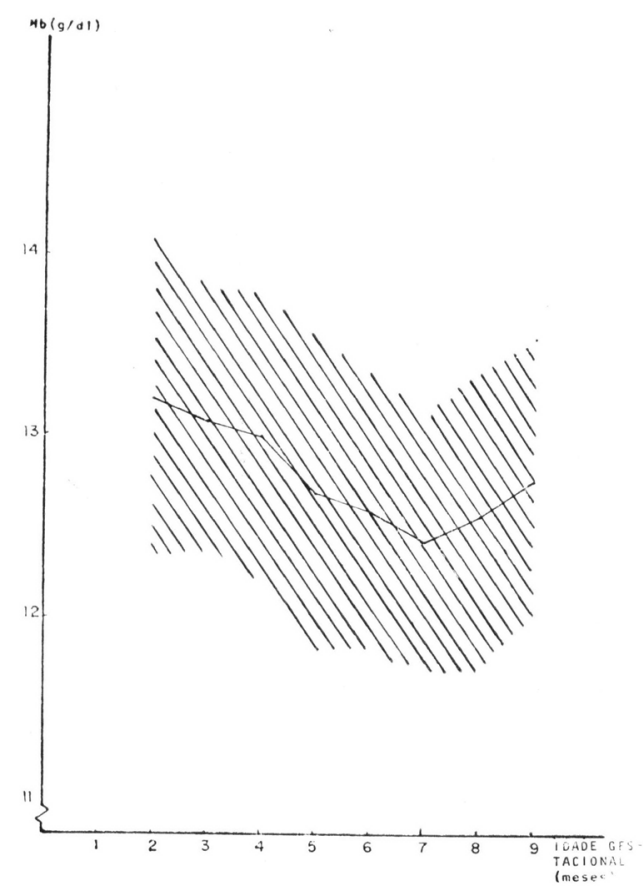

Fig. 1 - Distribuição da concentração de hemoglobina $\overline{(X} \pm 1 s)$, segundo idade gestacional, em população de grávidas atendidas em Centro de Saúde-Escola.



Fig. 2 - Distribuição da percentagem de hematócrito $\overline{(} \overline{\mathrm{X}} \pm 1 \mathrm{~s})$, segundo idade gestacional, em população de grávidas atendidas em Centro de Saúde-Escola.

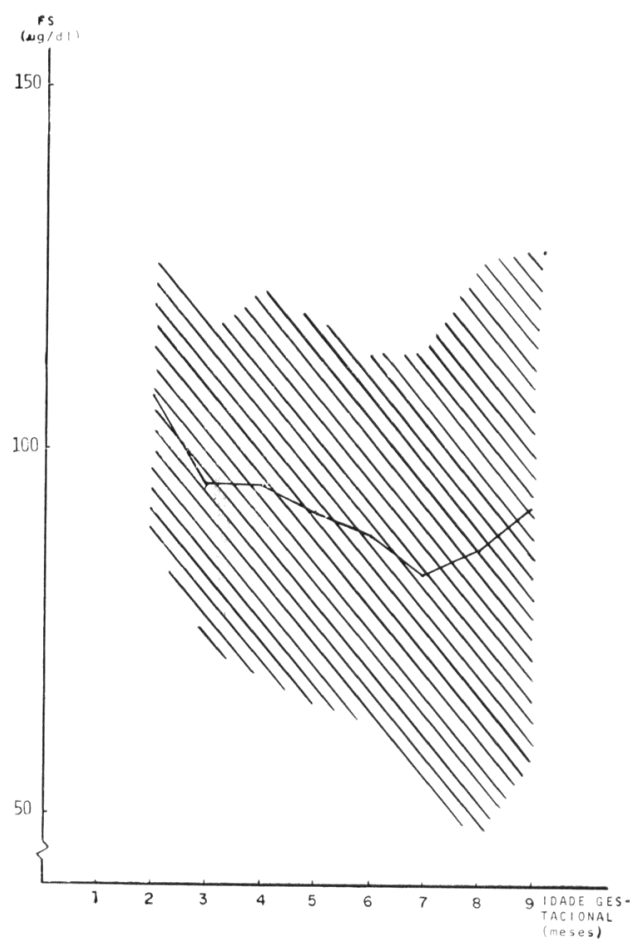

Fig. 3 - Distribuição da concentração de ferro sérico $(\bar{X} \pm 1 s)$, segundo idade gestacional, em população de grávidas atendidas em Centro de Saúde-Escola.

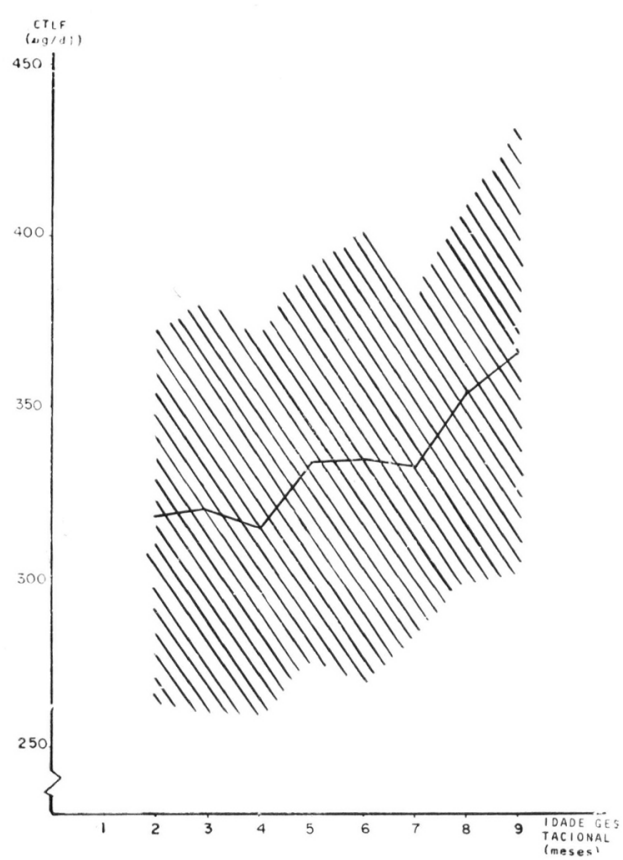

Fig. 4 - Distribuição da capacidade total de ligação de ferro ( $\bar{X} \pm 1 s)$, segundo idade gestacional, em gestantes atendidas em Centro de Saúde-Escola. 


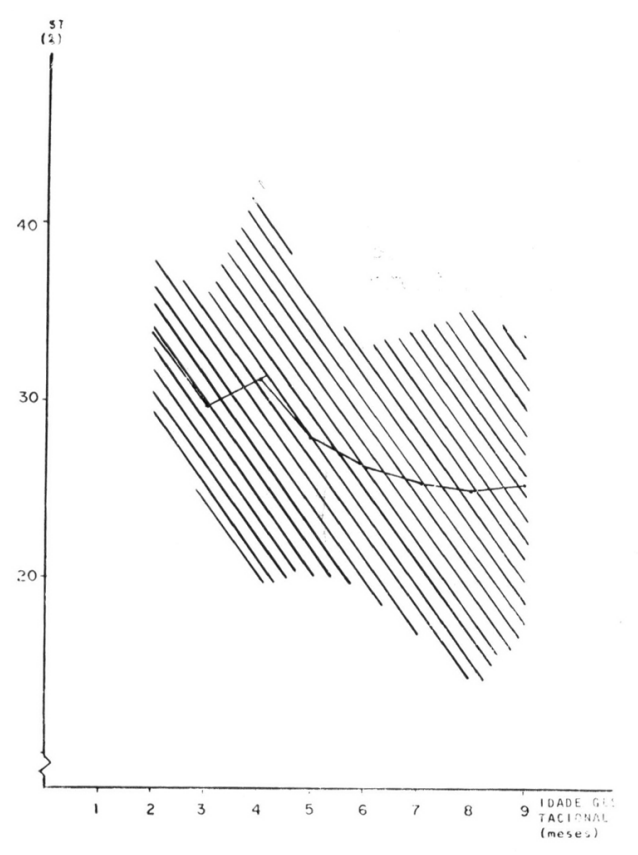

Fig. 5 - Distribuição da saturação de transferrina $\overline{(X} \pm 1 s)$, segundo idade gestacional, em gestantes atendidas em Centro de Saúde-Escola.

A partir dos resultados encontrados em relação à ST (Tabela - Figura 5), pode-se supor que, à medida que a idade gestacional avança, aumenta o risco da mulher se tornar ferro-deficiente e, a seguir, anêmica.

Verificamos, portanto, que mesmo em população de gestantes selecionadas pela caracteristica "ausência de anemia" ocorre uma diminuição importante das reservas de ferro, colocando-a em risco de se tornar ferro-deficiente e anêmica.

Dessa forma, mesmo entre grávidas que iniciaram e mantiveram na gestação con- centraçāo normal de hemoglobina, constatamos a incapacidade orgânica de manutenção dos estoques marciais à custa apenas do ferro alimentar.

Sendo o suprimento adequado de ferro prć-reçuisito para produção de massa adequada de hemoglobina, pode-se concluir que, para preservaçāo do estoque de ferro durante a gestação, mesmo para gestantes não anêmicas, é necessária uma suplementação.

\section{CONCLUSAOO}

Em estudo realizado en população de gestantes normais, não anêmicas, visando verificar as tendências na evoluçăo dos indicadores bioquimicos-hemoglobina, hematócrito, ferro sérico, capacidade total de ligação de ferro e saturação de transferrinaconcluimos que:

- Os valores médios de hemoglobina, de hematócrito e de ferro sérico diminuem até ao redor do 70 mês de gravidez, quando aumentam até $\rho$ final da gestação (Figuras 1, 2 e 3 ).

- A transferrina, medida através da capacidade total de ligação de ferro (Figura 4) aumenta durante todo o processo gestacional. Com relação à saturação da transferrina (Figura 5) observa-se diminuição do seu valor durante o decorrer de todo o processo gravídico.

- A relação entre ferro sérico e capacidade total de ligação de ferro (Figura 5), observada no decorrer da gravidez, sugere a existência de uma situaçāo de depleção dos estoques marciais em consequêencia do insuficiente fornecimento de ferro. 
SZARFARC, S.C. et al. Avaliação da concentração de ferro orgânico em uma população de grávidas. Rev. Saúde públ., S. Paulo, 17:200-7, 1983

SZARFARC, S. C. et al. [An assessment of organic iron concentration in pregnant women]. Rev. Saúde públ., S. Paulo, 17:200-7, 1983.

ABSTRACT: With the aim of discovering the biochemical alterations related to pregnancy and involving iron, the pre-natal case-histories of 250 pregnant women were studied. These women were non-anemic ( $\mathrm{Hb} \geqslant 11.0 \mathrm{~g} / \mathrm{dl}$ ) and free from pathological symptoms, both before and during pregnancy. The factors assessed: hemoglobin $(\mathrm{Hb})$, hematocrite $(\mathrm{Ht})$, serum iron (SI), total iron-binding capacity (TIBC) and transferrin saturation (TS) were plotted against gestational age, measured in weeks and in months. The $\mathrm{Hb}$ and $\mathrm{Ht}$ values diminished up to about the 7 th month, when they showed an increase which continued up to the end of the pregnancy. The same was observed in relation to SI. The TIBC showed an increase throughout pregnancy while the TS diminished throughout the whole period of gestation. The results observed justify the suggestion of iron supplementation as an easy public health strategy to be applied in the control of iron deficiency, even among non-anemic women.

UNITERMS: Pregnancy, nutritional state. Anemia, hypochromic.

\section{REFERENCIAS BIBLIOGRAFICAS}

1. ALMEIDA, P.A.M. et al. Identificação e avaliação dos fatores clínicos da gestação de alto risco. Rev. Saúde públ., S. Paulo, 9:417-25, 1975 .

2. ANDERSEN, H.T. \& BARKVE, H. Iron deficiency and miscular work performance. Scand. J. clin. Lab. Invest,, 25 (Suppl. 114): 3-62, 1970.

3. BOTHWELL, T.H. \& MALLIET, B. The determination of iron in plasma or serum. Biochem. J., 59:599-602, 1955.

4. CARR, M.C. Serum iron/TIBC in the diagnosis of iron deficiency anemia during pregnancy, Obstet. Gynec., $38: 602-8,1977$.

5. CHOPRA, J.G. \& BYAM, N.T.A. Anemia s:rvey in Trinidad and Tobago, Amer. J. publ. Hlth, 58:1922-36, 1968 .

6. CIARI Jr., C. et al. "Acreditaçăo" de serviços de pré-natal. Rev. Saúde públ., S. Paulo, 8:187-202, 1974.

7. CIARI Jr., C. et al. Avaliação quantitativa de serviços de pré-natal. Rev. Saúde públ., S. Paulo, 6:361-70, 1972.

8. COOK. D.J. Evaluation of intervention programs to combat iron deficiency. [Paper presented in the INACG Meeting, Göteborg, Sweden, 1977].
9. DELASCIO, D. \& ALMEIDA, P.A.M. Propedeutica da gestaçăo de alto risco. São Paulo, Livraria Manole, 1974.

10. DEVI, P.K. Observations on anemia in pregnancy in India. Israel J. med. Sci., $2: 494-8,1966$.

11. DONNELY, J.F, et al, Maternal, fetal and environmental factors in prematurity. Amer. J. Obstet. Gynec., 88:918-28, 1964.

12. EVERS, J.E.M. Premature births and iron deficiency. Ned. I. Geneesk, 110:2244-7, 1967. In: Excerpta med, Sect. $X$ : Obstet. Gynec., 20:320, 1967.

13. GANDRA, Y.R. \& BRADFIELD, R. Energy expenditure and oxigen handling of deficiency of anemic schoolchildren. Amer. J. clin. Nutr., 24:1451-6, 1970.

14. GILES, C. \& BURTON, H. Observations on prevention and diagnosis of anemia in pregnancy. Brit. med. J., 2:636-44, 1960.

15. GOOSEN, C.J. Anaemias of pregnancy in Africans. J. Obst. Gynaec. Brit. Emp., 68:994-9, 1961.

16. IIYTTEN, F.E. \& LEITCH, I. The physiology of human pregnancy. London, Blackwell, 1964. 
SZARFARC, S.C. et al. Avaliação da concentração de ferro orgânico em uma população de grávidas. Rev. Saúde pübl., S. Pa:ılo, 17:200-7, 1983

17. INTERNATIONAL NUTRITIONAL ANEMIA CONSULTATIVE GROUP. Guidelines for the eradication of iron deficiency anemia. Götcborg, Sweden, 1977.

18. KUMAR, R. Mec':anism of the anaemia of chronic infection. A re-examination of the role of functional iron deficiency and its causation. Ind. J. med. Res., 64:1046-56. 1978.

19. LAURELL, C.B. What is the function of transferrin in plasma? Blood, 6:183-7, 1951.

20. LAYRISSE, M. et al. Food iron absorption, a comparison of vegetable and animal foods. Blood, 33:430-43, 1969.

21. LINDER, M.C. \& MUNRO, H.N. The mechanism of iron absorption and it regulation. Fed. Proc., $36: 2017-23,1977$.

22. MATI, J.K.G. et al. The importance of anaemia of pregnancy in Nairobi, and the role of malaria in the aetiology of megaloblastic anaemia. $J$. trop. $M \in d$. Hyg., 74:1-8, 1971.

23. MORGAN, E.H. The role of transferrin in iron metabolism. Med. J. Aust., 2:322-5, 1972.

24. MUNRO, H.N. Iron absorption and nutrition. Fed, Proc. 36:2015-6, 1977.

25. NATIONAL ACADEMY OF SCIENCES. Recommended dietary allowances, 9 th ed. Washington, D.C., 1980.

26. NESBITT, E.L. \& AUBRY, R.H. High-risk obstetrics. Amer. J. Obstet. Gynec. 103:972-85, 1969 .
27. SAYERS, M.H. et al. The effect of acid ascorbic supplementation on the absorption of iron in maize, wheat, and soya. Brit. J. Haemat., 24:209-12, 1973.

28. SCHADE, A.L. et al. Saturated and unsaturated iron binding capacity of serum; rapid and reliable quantitative determination. Proc. Soc. exp. Biol., 87:448-8, 1954.

29. SECRETARIA DE ESTADO DA SAZDE. Coordenadoria de Saúde da Comunidade. Programa de assistencia da gestante. São Paulo, s.d. [mirneografado].

30. SZARFARC, S.C. Anemia ferropriva em parturientes e recém-nascido. Rev. Saude públ., S. Paulo, 8:369-74, 1974.

31. VARAT, M.A. et al. Cardiovascular effects of anemia. Amer. Heart J., 83:415-26, 1972 .

32. VENTURA, F. et al, Hemoglobina: dosagem pelo método da clanometahemoglobina. Uso de solução artificial para calibraçăo de aparelhos colorimétricos. Rev. Hosp. Clin. Fac. Med. S. Paulo, 22:303-4, 1967.

33. WEIMBERG, E.D. Infection and iron metabolism. Amer. J. olin. Nutr., $30: 1485-90$, 1977.

34. WORLD HEALTH ORGANIZATION. Expert Committee on the Prevention of Perinatal Mortality and Morbidity, Geneva, 1969. Report. Geneva, 1970. (Techn. Rep. Ser., 457).

Recebido para publicasão em 08/03/1982

Aprovado para publicasão em 0\%/03/1983 